JOURNAL OF SECURITY AND SUSTAINABILITY ISSUES

ISSN 2029-7017 print/ISSN 2029-7025 online

2019 September Volume 9 Number 1

http://doi.org/10.9770/jssi.2019.9.1(20)

Scopus

\title{
IMPACT OF SAFETY CONCERNS ON A LIFESTYLE
}

\author{
Mahrinasari, MS \\ Management of Department, Faculty of Economics and Business, The University of Lampung, Indonesia \\ E-mails: mahrina.sari@feb.unila.ac.id
}

Received 8 January 2019; accepted 28 June 2019; published 30 September 2019

\begin{abstract}
The main purpose of this research paper is too aware the people of Malaysia that how organic foods is beneficial and healthy compare to the traditional foods. Furthermore, the reason behind the research conducted in Malaysia was to discover the overall concept of Halal Foods. Mainly, the entire research paper evolves around the benefits of organic foods and its consumption. The most pertinent element is the healthy content and after that friendly environment strategies. Data were collected using a web-based survey to recruit participants from pools of consumer panels registered with a market research company. The technique which is used in this research is sampling technique. This study was limited as it was conducted only in the Malaysian city Kuala Lumpur, with the small sample size of 350 as well as the questionnaires was only comprising of close-ended questions of which the chances of inaccuracy is maximum. However, for future research the researcher should increase the sample size which represents the overall Malaysia by collecting the data from each region of Malaysia. Furthermore, the data collection should be done with the help of open-ended questions to reduce the inefficiency and inaccuracy of the study, more variables can also be counted in for evaluate the purchase intentions of the consumers.
\end{abstract}

Keywords: organic foods; consumption; foods; Hedonic consumption

Reference to this paper should be made as follows: Mahrinasari, MS 2019. Impact of safety concerns on a lifestyle, Journal of Security and Sustainability Issues 9(1): 269-280. http://doi.org/10.9770/jssi.2019.9.1(20)

JEL Classifications: L66, D16

\section{Introduction}

Healthy and safe food is a basic requirement of every human being. Paul \& Rana (2012) interrogated the consumer buying behavior in the framework of organic food consumption. This study reveals the fact that the consumer satisfaction and positive attitude towards the organic food is comprised of many important components. The most pertinent element is the healthy content. Primarily, quality of the food also satisfies the consumer mostly. Squires et al. (2001) investigated the organic food roles in New Zealand and Danish. The study found that the high price of the organic food is the obstacle for the Bangladeshi people in consuming organic food. Another major obstacle in approaching organic food is its unavailability. The result reveals that the food with organic label on it evokes the estimations that the food is low caloric. It also demonstrates that the label of organic foods is helpful for the retailers and manufactures that they are able to attract the customers towards organic foods because of its benefits.

Furthermore, Kareklas et al. (2014) interrogated the factors which emphasize a person to consume organic food. The study depicted that the organic foods has its own value among people. However, the nutritional content of the food and the environmental safety is the most important elements which people look after before consuming organic foods. Moreover, Gracia et al. (2014) analyzed the vigorous impact of diet and health labels on the consumer satisfaction, because the consumer is willing to purchase organic food for the sake of maximum satisfaction and maximum health safety. Results indicated that the hedonic attitude is satisfied by the 
diet labels without influencing the utilitarian attitudes towards healthy foods. It emphasizes on the importance of labels in food category. Moreover, consumer loyalty and attitudes are also a very essential element which predicts the human satisfaction level (Haseeb et al. 2019). The study revealed that the concern for healthy and safe foods shapes the utilitarian attitude whereas, the ecological welfare is an influencer for hedonic attitude. It further elaborates that the consumer always pays for its health and safety which means that organic foods is worthy because of its health benefits (Lee \& Goudeau, 2014; Myeni \& Mvuyana, 2018; Nkiru et al, 2018; Nurulhuda et al, 2018; Faridi, M.F.; Sulphey, M. M. 2019).

Nevertheless, Auger et al. (2010) examine the corporate responsibilities of the people that people really care for it or not. The results indicate that the consumers are not well aware about the corporate behavior that either it is good or bad. If they admire the product, they are going to pay for it without paying attention to the corporate roles of the organization. Nevertheless, Harper \& Makatouni (2002) investigated the consumer attitude and the productions effects on the farm animals. The final results indicate that the buying behavior of the consumers is composed of their values and perception. Consumer will pay for the products which are environmentally friendly and animal friendly and the product is not involved in violation of any ethical standards.

In the context of Malaysia, the awareness of the organic food and its benefits is at very low scale as compared to New Zealand and Danish, as it is the top producer of the organic foods in the world (Squires et al., 2001). In addition, this study is expected to aware people in Malaysia about the benefits of organic foods and its consumption. Because the people of Malaysia are more inclined towards traditional foods and are victimized of several diseases among which obesity is dominating. However, the importance of organic food is needed to be highlighted in Malaysian culture.

The main objective of this study is to aware Malaysian people about the benefits of the organic foods and how it is considered to be healthy as compared to the traditional foods. The purpose of conducting this research in the context of Malaysia is to explore the concept of Halal (legitimate) organic foods. The researches till now which investigated the organic food importance and influenced consumer behavior is done on all kinds of foods without Halal and Haram (illegitimate) concepts. But when it comes to the Malaysian contexts the only halal food consumption is allowed. Primarily, this study will be focusing the Halal organic foods consumption and its benefits. The entire study revolves around the importance of the organic foods and the attitude of the consumers. The most important factors of the study are the nutritional content, ecological welfare, natural content, sensory appeals and price and its influence on utilitarian and hedonic attitude which shapes the consumer purchase intention. Utilitarian attitude is the concern of safety and health needs whereas the hedonic attitude deals with the pleasure of consuming organic foods. Joshi \& Rahman (2015) conducted the research in which the consumption of the organic food was examined and evaluated. The research was on all kinds of foods regardless they are legitimate and illegitimate.

The significance of this study is that it is focused solely towards the legitimate organic foods which are going to be very beneficial. Specifically, this study will emphasize towards healthy diet and unprocessed foods and will create awareness among the people through which they will be able to overcome on their unhealthy lives and will inclined towards healthy eating through which they will be able to secure their lives from contagious diseases which are basically the causes of unhealthy life and uses of traditional foods which are highly rich in calories and are lacking in proteins, calcium and important vitamins. This study will cover all of the nutritional aspects which will surely become a reason of better life among people. Lee \& Yun (2015) interrogating the drastic gap between the attitudes and behavior and revealed that consumers compare the organic foods only with fruits and vegetables. They believe that organic food is only associated with fruits and vegetables whereas, the decision making is a complex behavior in order to purchase organic food or not. The values are associated with the decisions. 


\section{Literature Review}

\section{Nutritional Content:}

Johansson et al. (2014) investigated the nutritional knowledge on food labels and its impact on consumer buying behavior. This study was conducted in three major retailers' stores of United Kingdom. In addition, the nutritional awareness of the people was also examined in this study. About six product categories were studied in which $27 \%$ of those respondents were found who follow proper guidelines for daily amount. The statistical approach used in this research was regression analysis. The findings reflected that $28 \%$ of the shoppers pay attention to the nutritional knowledge mentioned on the food labels of the product. The study also revealed that the people are inclined towards healthy eating that's why they analyze thoroughly the nutritional charts and then take decisions. However, health component is always a dominating factor among purchasing the organic foods. Because the people believe that organic products are hygienic and energetic foods. Health and nutrition's are the most important determinant among college students while making purchase decisions (Dimitri \& Dettmann, 2012; Obiunu \& Rachael, 2018; Obodo, 2018; Obodo \& Anigbata, 2018; Olufemi, 2018).

Similarly, Bekele et al. (2016) conducted a research to examine the importance and influence of nutritional labeling on purchase decision. However, the results indicate that females are more willing to pay attention towards nutrition label while purchasing. Furthermore, people with more available time are also considered to be health conscious and pay fully attention on it. Diet conscious and health conscious people are also found to be look for the nutritional label on the products. Meanwhile, Miller et al. (2015) conducted a research in which they analyzed the impact of food labels on beef, poultry and seafood consumptions. The study reveals that $70 \%$ of the consumers perceive food label very helpful while making purchase decision, and the remaining $30 \%$ found to be insufficient of food labels. Consequently, those people who found food labels as an important aspect are those who are more likely towards healthy and nutritious consumption and more frequent buyers of meat and other products as compare to those who found less focused on health and nutritional concerns.

\section{H0: Nutritional content has the significant impact on the buying behavior of consumers of organic food. Sensory Appeal:}

Furthermore, Pham et al. (2019) interrogated the impact of diet and health labels on consumer taste and satiation. The study was conducted at the University of Illinois at Urbana Champaign. However, six weeks' field experiment in the cafeteria of this university took place. The nature of the study is found to be qualitative and quantitative because the data collection was done through the experimental methods and the respondents were asked to fill in the questionnaires. Six low calorie desserts were selected and the entire study revolves around it. In addition, the collected data was analyzed with the help of statistical tools among which the P test analyzed played the most significant role in drawing the conclusions. However, the results depict that diet labels can improve the taste of less healthy foods which satisfies the hedonic attitude without influencing the utilitarian attitude towards healthy foods. The most essential factors which played versatile role in the entire study were advertising, health labels, satiation, taste etc. Likewise, Hartley et al. (2013) conducted a research with respect to the fruits and vegetables consumption by individual. The factors covered in this study are sensory appeal, familiarity and habit, social interaction, cost availability, time constraints, personal ideology, media, advertising and health. The study reveals that food is not just consume for the nutrient purpose but for excitement and pleasure. According to the research taste, texture, quality, smell and appearance are found to be influential factors. These are the factors which stimulate people to buy fruits and vegetables.

Similarly, Joshi \& Rahman (2015) investigated the consumer motives, intentions and believe of consumers regarding organic food. The results reveal that sensory factor is the most important factor while making purchase decision next to price and safety. It also reveals that people who are price conscious are less inclined to buy organic food, contrary people who are willing to experience new things and innovations are considered to be the frequent buyers of organic food and are go with the sensory appeal. Moreover, taste is one of the main factor organic food while making purchase decision because consumer associate the higher price with the quality of food in terms of taste that if its expensive so it must be taste better (Joshi \& Rahman, 2015). 


\section{H1: Sensory appeal has the significant impact on the buying behavior of consumers of organic food. Ecological welfare:}

Auger et al. (2010) interrogated the factors which motivates a consumer to purchase organic food or not to purchase it. Eight organic items which were mentioned for the research purpose were apple, carrot, chicken, beef, bread, pasta, eggs and yogurt. Primarily, the participants were those who purchase organic foods regularly. Nevertheless, the entire study depicts that the respondents feel the organic foods as the social and individual values among which the most pertinent factor is the major health concerns of the family. Moreover, the animals and the safety of the environment is also given prior importance by the people.

Harper \& Makatouni (2002) carried out a study in which they focused upon the buying behavior of consumers in relation to the production of food and its major effects on farm animals. This study highlights that many buyers initially had a misconception between the "organic" and "free-range" food and both of them were considered to be the same due to which there was a vast effect on the buying behavior of the consumers. All in all, the results depicted that the buying behavior of the consumers had a great impact on their perceptions, beliefs and ethical issues towards the organic food. However, the purchasers were majorly concerned about the food produced through animal-friendly methods and this factor was considered to be the main reason behind the purchase of organic food. However, Pomsanam et al. (2014) examined the determinants of regular and occasional consumers while making purchase decisions. The results show that ethical considerations are the most important factor of regular consumers.

\section{H2: ecological welfare has the significant impact on the buying behavior of consumers of organic food. Price:}

Moreover, Aschemann-Witzel \& Zielke, (2017) had a research to identify the answers of two main questions that are willingness to pay influence by the same set of factors that affects purchase intention of conventional food and does willingness to pay is vary according to the category of organic food. The questionnaires were comprising of open-ended questionnaires to analyze the real in the food category. They are more willing to pay according to the quality and brand of the product. Moreover, Paul \& Rana (2012) invested a consumer's willingness to pay with respect to the food quality certification. The result depicted that people who are more conscious about quality food and health meanwhile appointed the consultants to get information about nutrition and health getting from the fruits and vegetables. Consumers are ok with the fact of paying more for green and Halal food because they perceive that green food are more expensive as compare to other conventional food (Saleki \& Seyedsaleki, 2012).

Similarly, Wee et al. (2014) conducted a research on consumer's perception, purchase intention and actual purchase behavior of organic foods products. The intention of constructing this research was to determine the interrelation between consumer's perception, purchase intention and actual purchase behavior in terms of organic foods. The total of 288 questionnaires was filled by the respondents. The data was collected from the supermarket and the nearby district in Johor, Malaysia. The sampling technique used was convenient sampling method which generated $96 \%$ response rate. The results have depicted that consumer's perception has tremendous influence on purchase intention with respect to health, safety, environmental factors and animal welfare of the product. In which, actual buying behavior was more affected than consumer's perception due to factors of age, gender, income, education, residence was observed. Consequently, the findings helped marketers to develop effective marketing strategies to convince people on switching to the organic foods and to enhance the buying behaviors in Malaysia.

\section{H3: Price has insignificant impact on the buying behavior of consumers of organic food.}

\section{Natural content:}

Toong et al. (2015) investigated the factors that effect on intention to purchase towards green and Halal foods of the chicken meat industry in Malaysia. The influential factors are natural content, convenience, lack of knowledge of Halal and green foods, familiarity, price consciousness, attitudes towards purchasing and demographics 
profile. The nature of the research was qualitative research. There are 377 respondents and questionnaires made were for interviewing using simple random technique. The statistical approaches used were descriptive analysis, correlation and ANOVA. The benefits of the consumer's lifestyle with the increasing intention towards the Halal and green foods in terms of opting the chicken meat in consumer market will be observed in this study. Consequently, the study was conducted to get the knowledge of niche market towards the chicken meat in industry in Malaysia.

Bravo et al. (2013) carried out a research on 'eating green' motivation behind organic food consumption in Germany. However, lack of consumption of organic foods was observed due to the difference of opinions of professionals. Data was collected from the focus groups which show there was no direct relation between the consumption of organic foods and the environmental health and safety concerns. Moreover, non-rational discourses were encouraged and disseminated through the mass media. These discourses made a prohibition of enough use of organic foods and though consumption became limited. So, many consumers of organic food had stepped back due to these reasons. The research was conducted through interviews but was recorded as quantitative because some of the questions were asked in questionnaires too. Technically, the theme of this research was to highlight the complex and conservative decision about whether to consume organic food or not.

\section{H4: Natural content has the significant impact on the buying behavior of consumers of organic food}

Conceptual framework is presented below (Figure 1).

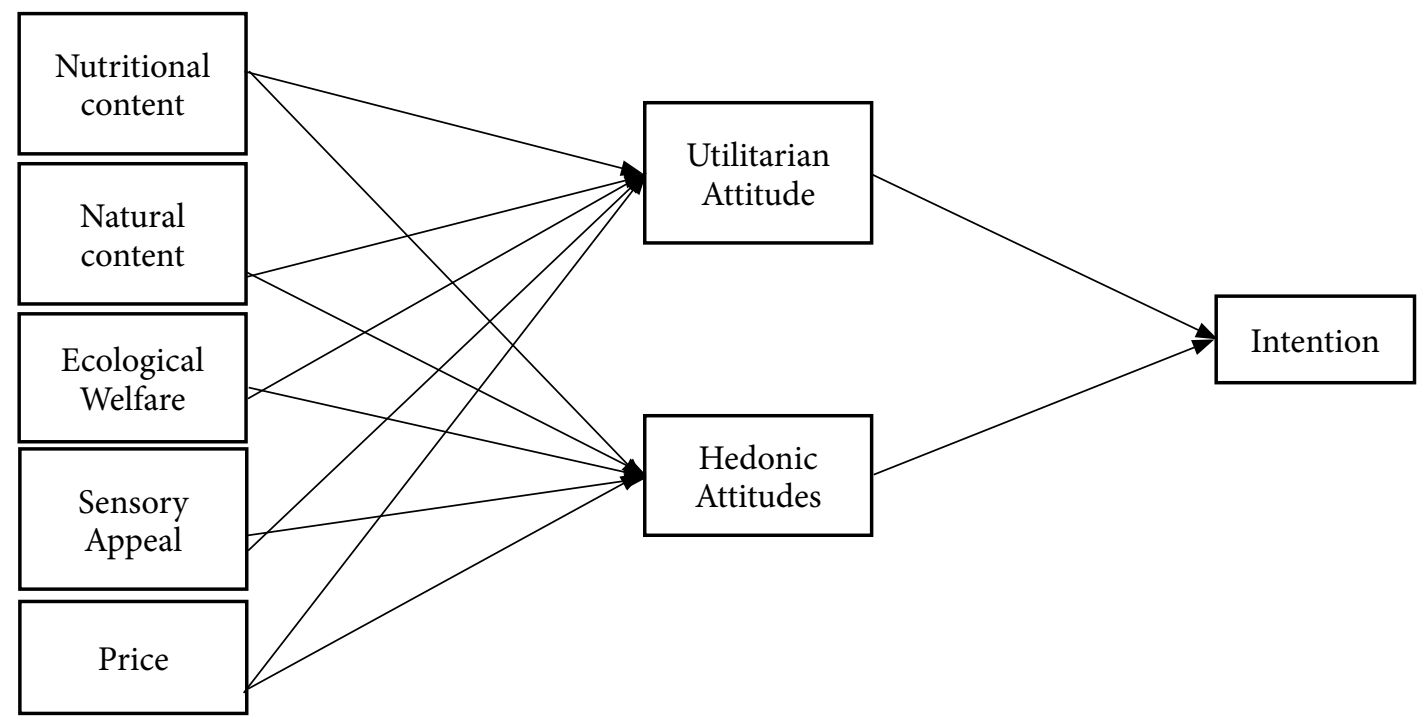

Figure 1. Conceptual framework

\section{Methodology}

Data were collected using a web-based survey to recruit participants from pools of consumer panels registered with a market research company. The samples for this study were primary grocery shoppers in the household who had ever purchased any food product labeled "organic." A sample of respondents who meet the specific sample criteria was invited by email to participate in the study.

The data was collected from the university students and other students that come under age bracket of questionnaire. Online questionnaires were created and targets more than 350 respondents online on social networking sites and through emails. Age bracket which was used were in the questionnaire was 18 to 30 young generation. 370 people were targeted to response on the questionnaire and after excluding outliers and missing responses 350 appropriate response were recorded, 350 showed great response to study. 
Non random sampling technique is used in the research paper for this study. The findings were that students' approval and reliability towards the study by using 5-point Likert scale shifting from (1) 'strongly disagree', (2) 'disagree', (3) 'neutral', (4) 'Agree', (5) 'Strongly Agree'. Questionnaire was created on Google docs and was distributed on email and social sites to all the respondents. Only electronic medium is used to collect data,

The research instrument which is used in this research is adapted from the previous article It contains 8 components that states the consumer behavior towards organic food and measure variables.

Table 1. Profile of respondents $(\mathrm{N}=350)$

\begin{tabular}{|c|c|c|}
\hline Demographic items & Frequency & Percentile \\
\hline Age & & $88.3 \%$ \\
\hline $18-25$ & 310 & $12 \%$ \\
\hline $26-30$ & 41 & $55.3 \%$ \\
\hline Gender & & $44.7 \%$ \\
\hline Male & 194 & \\
\hline Female & 156 & $2.3 \%$ \\
\hline Qualification & 8 & $8.3 \%$ \\
\hline Matric & 29 & $62.7 \%$ \\
\hline Intermediate & 220 & $26.5 \%$ \\
\hline Under Graduate & 93 & \\
\hline Graduate & & \\
\hline
\end{tabular}

The sample represented the responses of the students and other users of organic food from different areas and in total 350 questionnaires were filled and returned. The details of demographic profiles are presented in table 1. This table is divided in 3 parts Age, Gender and Qualification. As seen from demographic characteristics of age group shows that $88.3 \%$ respondents were falling in the age bracket of (18-25) and rest $12 \%$ respondent were falling in the age bracket of (26-30) In terms of gender, the $55.3 \%$ of respondents were male, while $44.7 \%$ were female hence equally distributed. The minority of respondent were from matric which is $2.3 \%$ then intermediate respondents were $8.3 \%$. The majority of the respondent were undergraduate $62.7 \%$ whereas, $26.5 \%$ were graduate.

\section{Analysis \& Results}

To make sense out of this data they have Smart PLS software version 3.1.6 is used and structure modeling equation SEM was used in this software. A sample size of 320 questionaires was used in this study. However, PLSSEM is specifically very effective and suitable in analyzing the complexed behavioral and structural models (Hair et al., 2011; Wang \& Yang 2018; Takele, 2018; Stark \& Yahaya, 2018; Habib \& Mucha Sr 2018). Furthermore, table 2 depicts the results of measurement models whereas, table 3 elaborates the summary of statistics. Nevertheless, the model of measurement went through several tests for the proper composition of validity and reliability as mentioned by Hair et al. (2011). Moreover, convergent validity is created for the construct is AVE (average varaince extracted) is above the threshold i.e 0.50 (Fornell and Larcker, 1981) all construct passes this test sucessfully as mentioned in the table 2 . Moreover, all of the items of this study have loading more than 0.70 which is relevant and eligible (see table 3 ) along with their respective variables (see table 4 ). Nevertheless, scale validity is analyzed with the help of Cronbach's $\alpha$ and composite reliability which is above 0.70 and indicates that it is reflecting very positive and eligible results. All of the constructs are showing the AVE about 0.5 which is in the acceptable range. Table 2 is demonstrating the variables reliability and compatibility individually as well as collectively and in both cases it indicates the level of acceptance and eligible demonstration. Which interprets that the constructs and variables composed for the study is quite authentic and reliable on which the entire study can be depended. 
Table 2. Summary Statistics

\begin{tabular}{|c|c|c|c|c|c|c|c|c|}
\hline \multicolumn{9}{|c|}{ Correlation Matrix } \\
\hline & BI & ECO & HED & NAT & NUT & PR & SEN & UTI \\
\hline BI & $\mathbf{0 . 8 1 5}$ & & & & & & & \\
\hline ECO & 0.497 & $\mathbf{0 . 7 4 7}$ & & & & & & \\
\hline HED & 0.411 & 0.317 & $\mathbf{0 . 8 3 4}$ & & & & & \\
\hline NAT & 0.565 & 0.566 & 0.188 & $\mathbf{0 . 8 2 3}$ & & & & \\
\hline NUT & 0.639 & 0.571 & 0.200 & 0.743 & $\mathbf{0 . 9 1 5}$ & & & \\
\hline PR & 0.221 & 0.185 & 0.221 & 0.214 & 0.277 & $\mathbf{0 . 9 2 5}$ & & \\
\hline SEN & 0.655 & 0.549 & 0.377 & 0.542 & 0.692 & 0.341 & $\mathbf{0 . 8 4 4}$ & \\
\hline UTI & 0.611 & 0.530 & 0.186 & 0.673 & 0.755 & 0.231 & 0.599 & $\mathbf{0 . 8 9 9}$ \\
\hline
\end{tabular}

The bold values show the significance of each constructs which highly indicates that the value is above 0.5. Furthermore, each bold value of the variables highlights that the diagonal elements is the square root of AVE. However, the bold values criteria are that it should be above then the rest of the mentioned values and the highlighted values above is greater than the rest of the values which shows the eligibility of the constructs.

Table 3. Loadings and Cross Loadings

\begin{tabular}{|c|c|c|c|c|c|c|c|c|}
\hline & BI & ECO & HED & NAT & NUT & PR & SEN & UTI \\
\hline Eco_1 & 0.403 & 0.744 & 0.241 & 0.488 & 0.471 & 0.142 & 0.445 & 0.437 \\
\hline Eco_2 & 0.408 & 0.791 & 0.245 & 0.453 & 0.456 & 0.176 & 0.465 & 0.442 \\
\hline Eco_3 & 0.280 & 0.698 & 0.219 & 0.317 & 0.336 & 0.077 & 0.298 & 0.319 \\
\hline Eco_4 & 0.379 & 0.754 & 0.242 & 0.412 & 0.429 & 0.147 & 0.413 & 0.369 \\
\hline Pr_1 & 0.152 & 0.181 & 0.176 & 0.158 & 0.223 & 0.900 & 0.291 & 0.167 \\
\hline Sen_1 & 0.480 & 0.409 & 0.171 & 0.391 & 0.547 & 0.226 & 0.814 & 0.459 \\
\hline Sen_2 & 0.458 & 0.461 & 0.324 & 0.424 & 0.531 & 0.279 & 0.825 & 0.457 \\
\hline Sen_3 & 0.623 & 0.507 & 0.336 & 0.538 & 0.673 & 0.318 & 0.902 & 0.601 \\
\hline Sen_4 & 0.623 & 0.467 & 0.410 & 0.454 & 0.568 & 0.312 & 0.831 & 0.487 \\
\hline beh_1 & 0.840 & 0.437 & 0.472 & 0.462 & 0.541 & 0.282 & 0.579 & 0.504 \\
\hline beh_2 & 0.873 & 0.415 & 0.301 & 0.495 & 0.574 & 0.217 & 0.583 & 0.568 \\
\hline beh_3 & 0.739 & 0.308 & 0.301 & 0.319 & 0.315 & 0.071 & 0.379 & 0.273 \\
\hline beh_4 & 0.801 & 0.432 & 0.253 & 0.525 & 0.588 & 0.106 & 0.547 & 0.573 \\
\hline hed_2 & 0.358 & 0.321 & 0.905 & 0.155 & 0.207 & 0.246 & 0.412 & 0.197 \\
\hline hed_4 & 0.331 & 0.187 & 0.755 & 0.165 & 0.110 & 0.096 & 0.176 & 0.096 \\
\hline nat_1 & 0.406 & 0.424 & 0.191 & 0.782 & 0.516 & 0.178 & 0.371 & 0.437 \\
\hline nat_2 & 0.566 & 0.522 & 0.162 & $\mathbf{0 . 8 8 7}$ & 0.763 & 0.179 & 0.565 & 0.707 \\
\hline nat_3 & 0.386 & 0.437 & 0.113 & 0.796 & 0.496 & 0.177 & 0.354 & 0.455 \\
\hline nut_1 & 0.581 & 0.510 & 0.184 & 0.705 & 0.932 & 0.269 & 0.642 & 0.711 \\
\hline nut_2 & 0.608 & 0.539 & 0.179 & 0.691 & 0.934 & 0.282 & 0.652 & 0.728 \\
\hline nut_3 & 0.613 & 0.539 & 0.201 & 0.687 & 0.925 & 0.267 & 0.645 & 0.703 \\
\hline nut_4 & 0.534 & 0.501 & 0.166 & 0.636 & 0.868 & 0.190 & 0.591 & 0.614 \\
\hline pr_2 & 0.243 & 0.165 & 0.226 & 0.229 & 0.283 & 0.949 & 0.334 & 0.249 \\
\hline uti_2 & 0.485 & 0.485 & 0.149 & 0.562 & 0.666 & 0.222 & 0.517 & 0.872 \\
\hline uti_3 & 0.524 & 0.431 & 0.145 & 0.628 & 0.679 & 0.228 & 0.522 & 0.912 \\
\hline uti_4 & 0.629 & 0.511 & 0.203 & 0.622 & 0.691 & 0.177 & 0.574 & 0.912 \\
\hline
\end{tabular}

The loadings of each construct are ought to be very significant. Primarily, as per the recommended threshold point which is 0.55 each and every construct of this study is showing the above level indication which mean that the reliable composition and significance is quite relevant and in the premises of acceptance. However, the 
loading of the constructs is done for examining the level of significance of the study variables which will lead the variables to the final conclusion. This test is the most essential one which is examining the threshold points of the variable that either it is going to be effective throughout the study or not.

Table 4. Heterotrait-Monotrait Ratio (HTMT) Results

\begin{tabular}{|c|c|c|c|c|c|c|c|c|}
\hline & BI & ECO & HED & NAT & NUT & PR & SEN & UTI \\
\hline BI & & & & & & & & \\
\hline ECO & 0.615 & & & & & & & \\
\hline HED & 0.588 & 0.464 & & & & & & \\
\hline NAT & 0.671 & 0.733 & 0.289 & & & & & \\
\hline NUT & 0.700 & 0.681 & 0.258 & 0.846 & & & & \\
\hline PR & 0.239 & 0.233 & 0.287 & 0.262 & 0.307 & & & \\
\hline SEN & 0.744 & 0.674 & 0.482 & 0.631 & 0.763 & 0.392 & & \\
\hline UTI & 0.682 & 0.649 & 0.243 & 0.784 & 0.830 & 0.264 & 0.678 & \\
\hline
\end{tabular}

Haterotrait Monotrait ratio (HTMT) is indicating that none a single value is above 0.83 . As the threshold suggested by Hair et al. (2011) is that the assessed variance inflation factors should be below 0.90 and the above mention table 4 elucidates that each if the constructed variable is lying between 0.2 till 0.8 . This is indicating the acceptance level of the test. Nutritional Content factor is again dominating with the highest ranked score i.e. 0.84 . The test is meant to acquire and analyze the most significant variables and to check its reliability and compatibility.

Table 5.

\begin{tabular}{|c|c|c|c|}
\hline Regression Path & Effect Type & SRW & Remarks \\
\hline ECO -> HED & Direct & 0.21 & Supported \\
\hline ECO -> UTI & Direct & 0.073 & Supported \\
\hline HED -> BI & Direct & 0.304 & Supported \\
\hline NAT -> HED & Direct & -0.006 & Supported \\
\hline NAT - > UTI & Direct & 0.221 & Not Supported \\
\hline NUT -> HED & Direct & -0.195 & Supported \\
\hline NUT - UTI & Direct & 0.0464 & Supported \\
\hline PR -> HED & Direct & 0.117 & Supported \\
\hline PR -> UTI & Direct & 0.001 & Supported \\
\hline SEN -> HED & Direct & 0.36 & Supported \\
\hline SEN -> UTI & Direct & 0.119 & Supported \\
\hline UTI -> BI & Direct & 0.558 & \\
\hline
\end{tabular}

The table 5 exhibits the regression model which is basically developing the hypothesis of each variable and as per the standardized regression weight of each factor the results are mostly favorable and few unfavorable. SRW test is the eligibility criterion test which highlights whether the factor is going to play supportive role in entire study or not. It highly measures the significance of the variable. Hypothesis 1 is showing the relationship between the ecological welfare and the hedonic attitude and the results depicts that both of these variables are having positive relationship among them which means that both of the constructs moves in the same direction and are supportive which means that the expected results of these constructs quite significant which elaborates that when the ecological welfare emphasizes the hedonic attitude of the consumers. It reflects the idea that people re concern with the ethical standards and environmental safety. These two variables shape the hedonic attitude of the consumers. However, the $\mathrm{H} 2$ is the relationship between ecological and utilitarian attitude which shows the direct correlation and supportive results. Here it means that the satisfaction level of the consumer is highly associated with the environmental safety products. Nevertheless, H3 is reflecting the relationship between hedonic attitude and behavioral intention which depicts the positive and supportive relationship. It means 
that the behavior of consumer is shaped when his or her hedonic attitude is satisfied and then he or she try to consumer organic food. Moreover, H4 is comprised of natural content and hedonic attitude which shows the negative relationship between them and the significance level is so minimal that it is categorized in not supported range. Which conceptually means that the product made up of purely natural and healthy content is unable to satisfy the hedonic attitude which actually means that people are unable to enjoy pleasure in the organic food consumption? H5 is based on natural content and utilitarian attitude whereas, H6 is comprised of nutritional content and hedonic attitude both are showing positive relationship and are having significant impact. This means consumer utilitarian need is satisfied when he enjoys the natural content in organic food and the hedonic need is also satisfied when there is the nutritional content availability in the organic food. H7 depicts that the nutritional content is supported with the utilitarian attitude. Which means both constructs haves a significant impact and moves in the same direction. $\mathrm{H} 8$ and $\mathrm{H} 9$ are comprised of relationships between price and hedonic attitude and price with utilitarian behavior respectively. It interprets that $\mathrm{H} 7$ hypothesis is supportive in its nature and has positive impact among each other whereas, $\mathrm{H} 9$ depicts the fact that price and utilitarian attitude is having unsupportive impact which shows the level of insignificance. It means that increment in price will show increment in utilitarian attitude with minimal significance i.e. change. Whereas, H10, H11 and H12 shows the supportive relationship with positive correlation bonding. Here it emphasizes that sensory appeal haves the significant impact on the hedonic attitude same is the case with sensory appeal and utilitarian behavior. However, utilitarian attitude and behavioral intention also depicts the significant impacts and positive correlation.

\section{Conclusion}

The primary motive of the study is to identify the consumer buying behavior of organic food with respect to health and safety concern in the framework of Malaysia. The entire study covers the six main variables that is the nutritional content, ecological welfare, natural content, sensory appeals and price which all together influence the hedonic and utilitarian attitude then shape the purchase intension of the consumer. Moreover, the 36 research questions were adopted from the article to collect the data from random population to analyze their purchase intension of organic food. The sample size of the study was 370 from which 350 appropriate responses were collected and the whole data collection process was done through social media by online questionnaires. After the collection of data, the various test has been applied to test the reliability and eligibility of the variables as well as the study. Firstly, the test which has been run is Cronbach's alpha to analyze the reliability of instruments and collected data which shows the positive result. Secondly, the correlation test has been applied to check the connectivity of each factor to identify the purchase intention of the consumers. Thirdly, loading and cross loading test has been run to identify the significance level of each variable. After that the Haterotrait Monotrait ratio and regression model applied to verify the reliability of most significant variable and the most supportive variable of the entire study. However, from the above analysis the researcher concluded that nutritional content is dominating in each analysis which has an influence on utilitarian attitude that clearly indicates people consume organic food for the sake of satisfaction and good health. Furthermore, price is another factor which has the strong impact on utilitarian attitude. Whereas, the insight of ecological and sensory appeal has the direct impact on the hedonic attitude.

Form the findings, it should be recommended to the grower as well as the provider to keep organic foods free from any sort of pesticides and chemicals which convert natural, hygienic and healthy food into artificial and unhealthy which will never entertain those people whose first priority of food consumption is nutrition, health and fitness. Whereas, the prices of organic food should be kept affordable for the consumers because it is another variable of the study which plays a versatile role in emerging the purchase intention of the people that is why the sellers should compromise on prices for retaining and maintaining the long-term relationships with the customers. 


\section{References}

Aikaterini Makatouni. (2002). What motivates consumers to buy organic food in the UK?: Results from a qualitative study. British Food Journal, 104(3/4/5), 345-352, Available at: https://doi.org/10.1108/00070700210425769

Aschemann-Witzel, J., \& Zielke, S. (2017). Can't buy me green? A review of consumer perceptions of and behavior toward the price of organic food. Journal of Consumer Affairs, 51(1), 211-251. Available at: https://doi.org/10.1111/joca.12092

Aschemann-Witzel, J., \& Zielke, S. (2017). Can't buy me green? A review of consumer perceptions of and behavior toward the price of organic food. Journal of Consumer Affairs, 51(1), 211-251. Available at: https://doi.org/10.1111/joca.12092

Auger, P., Devinney, T. M., Louviere, J. J., \& Burke, P. F. (2010). The importance of social product attributes in consumer purchasing decisions: A multi-country comparative study. International Business Review, 19(2), 140-159. Available at: https://doi.org/10.1016/j. ibusrev.2009.10.002

Bekele, A. D., Beuving, J., \& Ruben, R. (2016). Food choices in Ethiopia: does nutritional information matter?. International journal of consumer studies, 40(6), 625-634. Available at: https://doi.org/10.1111/ijcs.12278

Bravo, C. P., Cordts, A., Schulze, B., \& Spiller, A. (2013). Assessing determinants of organic food consumption using data from the German National Nutrition Survey II. Food quality and Preference, 28(1), 60-70. Available at: https://doi.org/10.1016/j.foodqual.2012.08.010

Dimitri, C. and Dettmann, R.L. (2012) Organic Food Consumers: What Do We Really Know about Them? British Food Journal, 114, 1157-1183. Available at: https://doi.org/10.1108/00070701211252101

Faridi, M.F., Sulphey, M. M. (2019). Food security as a prelude to sustainability: a case study in the agricultural sector, its impacts on the Al Kharj community in The Kingdom of Saudi Arabia. Entrepreneurship and Sustainability Issues, 6(3), 1336-1345. https://doi. org/10.9770/jssi.2019.6.3(34)

Gracia, A., Barreiro-Hurlé, J., \& Galán, B. L. (2014). Are local and organic claims complements or substitutes? A consumer preferences study for eggs. Journal of Agricultural Economics, 65(1), 49-67. Available at: https://doi.org/10.1111/1477-9552.12036

Hair, J. F., Ringle, C. M., \& Sarstedt, M. (2011). PLS-SEM: Indeed a silver bullet. Journal of Marketing theory and Practice, 19(2), 139-152. Available at: https://doi.org/10.2753/mtp1069-6679190202

Habib, A., \& Mucha Sr, M. (2018). The Lifecycle and Effective Communication of CSR to the Stakeholder and the Public. International Journal of Economics, Business and Management Studies, 5(1), 1-8.

Haseeb, M., Hussain, H. I., Ślusarczyk, B., \& Jermsittiparsert, K. (2019). Industry 4.0: A solution towards technology challenges of sustainable business performance. Social Sciences, 8(5), 154.

Harper, G. C., \& Makatouni, A. (2002). Consumer perception of organic food production and farm animal welfare. British Food Journal, 104(3/4/5), 287-299. Available at: https://doi.org/10.1108/00070700210425723

Hartley, L., Igbinedion, E., Holmes, J., Flowers, N., Thorogood, M., Clarke, A., ... \& Rees, K. (2013). Increased consumption of fruit and vegetables for the primary prevention of cardiovascular diseases. Cochrane Database of Systematic Reviews, (6).

Hyun-Joo Lee, Cynthia Goudeau, (2014). Consumers' beliefs, attitudes, and loyalty in purchasing organic foods: The standard learning hierarchy approach. British Food Journal, 116(6), 918-930. Available at: https://doi.org/10.1108/bfj-02-2013-0030

Johansson, E., Hussain, A., Kuktaite, R., Andersson, S., \& Olsson, M. (2014). Contribution of organically grown crops to human health. International Journal of Environmental Research and Public Health, 11(4), 3870-3893. Available at: https://doi.org/10.3390/ ijerph110403870

Joshi, Y., \& Rahman, Z. (2015). Factors affecting green purchase behaviour and future research directions. International Strategic management review, 3(1-2), 128-143. Available at: https://doi.org/10.1016/j.ism.2015.04.001

Justin Paul, Jyoti Rana, (2012). Consumer behavior and purchase intention for organic food. Journal of Consumer Marketing, 29(6), 412-422. Available at: https://doi.org/10.1108/07363761211259223

Kareklas, I., Carlson, J. R., \& Muehling, D. D. (2014). "I eat organic for my benefit and yours": Egoistic and altruistic considerations for purchasing organic food and their implications for advertising strategists. Journal of Advertising, 43(1), 18-32. Available at: https:// doi.org/10.1080/00913367.2013.799450

Lee, H. J., \& Yun, Z. S. (2015). Consumers' perceptions of organic food attributes and cognitive and affective attitudes as determinants of their purchase intentions toward organic food. Food Quality and Preference, 39, 259-267. Available at: https://doi.org/10.1016/j. 
Makatouni, A. (2002). What motivates consumers to buy organic food in the UK? Results from a qualitative study. British Food Journal, 104(3/4/5), 345-352. Available at: https://doi.org/10.1108/00070700210425769

Myeni, S. L., \& Mvuyana, B. Y. (2018). Participatory Processes in Planning for Self-Help Housing Provision in South Africa: Policies and Challenges. International Journal of Public Policy and Administration Research, 5(1), 24-36.

Miller, L. M. S., \& Cassady, D. L. (2015). The effects of nutrition knowledge on food label use. A review of the literature. Appetite, 92, 207-216. Available at: https://doi.org/10.1016/j.appet.2015.05.029

Nkiru, N., Sidi, C. P., \& Abomeh, S. (2018). Impact of Information and Communication Technology on the Performance of Deposit Money Banks in Nigeria. International Journal of Management, 7(4), 225-239.

Nurulhuda, S., Hasan, R., \& Mohd, A. (2018). Does Gold Price Lead or Lags Islamic Stock Market and Strategy Commodity Price? A Study from Malaysia. International Journal of Business, 5(6), 146-163.

Obiunu, J. J., \& Rachael, O. (2018). Attitudinal Disposition of Students Towards the Personality Traits of Counsellors. A Case Study of Public Secondary Schools in Delta State, Nigeria. International Journal of Emerging Trends in Social Sciences, 3(2), 52-56.

Obodo, N. A. (2018). Content Analysis of Time Management as a Tool for Corporate Effectiveness. International Journal of Applied Economics, Finance and Accounting, 2(2), 36-39.

Obodo, N. A., \& Anigbata, D. O. (2018). Challenges of Implementing Electronic Governance in Public Sector Organizations in Nigeria. International Journal of Applied Economics, Finance and Accounting, 2(1), 30-35.

Olufemi, A. S. (2018). Measuring and Assessing the State of Technological Innovations and the Level of Interaction between Rice Processors and Stakeholders in Rice Processing Industry in Nigeria. International Journal of Business, Economics and Management, 5(6), 164-175.

Pham, N., Morrin, M., Bublitz, M.G (2019). Flavor halos andconsumer perceptions of food healthfulness. European Journal of Marketing, 53(4), 685-707, Available at: https://doi.org/10.1108/EJM-10-2017-0663

Pomsanam, P., Napompech, K., Suwanmaneepong, S. (2014). Factors Driving Thai Consumers' Intention to Purchase Organic Foods, Asian Journal of Scientific Research, 7(4), 434. Available at: https://doi.org/10.3923/ajsr.2014.434.446

Squires, L., Juric, B. and Cornwell, T.B. (2001). Level of market development and intensity of organic food consumption: crosscultural study of Danish and New Zealand consumers. Journal of Consumer Marketing, 18(5), 392-409. Available at: https://doi. org/10.1108/07363760110398754

Saleki, Z. S., \& Seyedsaleki, S. M. (2012). The main factors influencing purchase behaviour of organic products in Malaysia. Interdisciplinary Journal of Contemporary Research in Business, 4(1), 98-116.

Stark, A., \& Yahaya, F. H. (2018). The Body Concept of Traditional Healers in West Sumatra. International Journal of Asian Social Science, 8(12), 1180-1185.

Toong, F. W., Khin, A. A., \& Khatibi, A. (2015). Impact of changing consumer lifestyles on intention to purchase towards green and halal foods of the chicken meat industry in Malaysia. International Journal of Marketing Studies, 7(6), 155-158. Available at: https:// doi.org/10.5539/ijms.v7n6p155

Takele, A. (2018). Ethiopian Urban Land Lease Policy Analysis Implementation: Case Study on AA City Administration. International Journal of Social Sciences Perspectives, 2(2), 96-100.

Wee, C. S., Ariff, M. S. B. M., Zakuan, N., Tajudin, M. N. M., Ismail, K., \& Ishak, N. (2014). Consumers perception, purchase intention and actual purchase behavior of organic food products. Review of Integrative Business and Economics Research, 3(2), 378.

Wang, K., \& Yang, Z. (2018). The Research on Teaching of Mathematical Understanding in China. American Journal of Education and Learning, 3(2), 93-99. 
Dr. MAHRINASARI MS is an Associate Professor of Marketing and an Associate Dean of Academic and Cooperation Affair, Faculty of Economics and Business, The University of Lampung. She got a PhD in Marketing and CSR, from Universitas Gadjah Mada, Indonesia in February 2014, and a Master degree in Business Administration, from College of Business, University of Illinois at Urbana-Champaign USA in January 1995. She was a member of American Marketing Association in 1994 - 2021. She is an AGBA Vice President for Southern Indonesia (http://agba.us/leadership.html) since 2016. Her research interests are Marketing and CSR; Consumer Behavior; Entrepreneurship; Innovation and Sustainability.

ORCID ID: https://orcid.org/0000-0001-6333-6423 